\title{
KVALITET ELEKTRIČNE ENERGIJE NA 0,4 kV STRANI ENERGETSKOG TRANSFORMATORA
}

\section{POWER QUALITY AT 0.4 kV SIDE OF POWER TRANSFORMER}

\author{
Mile Racić, Fakultet tehničkih nauka, Novi Sad
}

\section{Oblast - ELEKTROTEHNIKA I RAČUNARSTVO}

Kratak sadržaj - U ovom radu opisano je merenje $i$ analiza kvaliteta električne energije na $0,4 \mathrm{kV}$ strani transformatora. $U$ pitanju su trafostanice prenosnog odnosa 20(10)/0,4 kV. Prikazani su rezultati merenja, njihova analiza $i$ upoređivanje sa datim standardima za četiri trafostanice.

Ključne reči: Kvalitet električne energije, energetski transformator 20(10)/0,4 kV, mrežni analizator

Abstract - This paper describes measurements and analyses of power quality at $0.4 \mathrm{kV}$ side of power transformer. These are substations with a voltage ratio of $20(10) / 0,4 \mathrm{kV}$. The result of measurements, their analysis and comparison with the given standards for four substations are presented.

Keywords: Power quality, power transformer 20/10/0.4 kV, power quality analyser

\section{UVOD}

Kvalitet isporučene električne energije, sa aspekta elektrodistribucije, podrazumeva kvalitet napona na sabirnici na koju se priključuju razni potrošači. On podrazumeva da se osnovne karakteristike napona (efektivna vrednost, frekvencija, simetričnost i talasni oblik) drže u zadanim okvirima, odnosno sa nominalnim vrednostima u ustaljenom stanju EES-a.

$\mathrm{Na}$ karakteristike napona značajan uticaj imaju sami potrošači, naročito grupa nelinearnih potrošača, zatim tranzijentne pojave usled komutacija u EES, atmosferske pojave, kvarovi (kratki spojevi), nevreme, divlje životinje i dr. [1].

Kvalitet električne energije je vezan za odstupanje talasnih oblika napona i struja od idealnog prosto-periodičnog oblika. To savršeno napajanje bi bilo takvo napajanje, koje bi bilo uvek dostupno, bez prekida, sa frekvencijom i naponom uvek $u$ određenim granicama tolerancije i sa čistim sinusoidalnim talasnim oblikom.

Prema tome, kvalitet električne energije se može izraziti kao odstupanje od idealnog kvaliteta i to odstupanje se definiše preko pokazatelja kvaliteta električne energije.

Ukoliko kvalitet električne energije nije zadovoljavajući može se pojaviti dosta problema. Među najznačajnijim su oni vezani za uticaj harmonijskih izobličenja, kao što su:

\section{NAPOMENA:}

Ovaj rad proistekao je iz master rada čiji mentor je bio dr Vladimir Katić, redovni profesor.
- Pregrevanje nultog provodnika,

- Pregrevanje transformatora,

- Pregrevanje i nepravilan rad električnih motora,

- Uticaj harmonika na prekidače i zaštitne releje,

- Uticaj na elektronsku opremu,

- Uticaj na rad statičkih energetskih pretvarača,

- Uticaj na telekomunikacione veze,

- Naprezanje kondenzatorskih baterija za kompenzaciju reaktivne energije,

- Izobličenje mrežnog napona usled toka harmonijskih struja,

- Efekti toka harmonika struja kroz provodnike i sabirnice, id r.

\section{STANDARDI I PREPORUKE}

Većina razvijenih industrijskih zemalja sveta, kao i najznačajnije međunarodne organizacije su donele tehničke propise - standard sa navođenjem graničnih vrednosti osnovnih parametara kvaliteta električne energije od kojih zavisi stabilnost rada elektroenergetskog sistema (efektivna vrednost napona, frekvencija i s1.) [1,2]. Ostali parametri, su definisani pojedinačno ili u sklopu sveobuhvatnijih dokumenata o kvalitetu električne energije.

Ovi propisi su u obliku ili obavezujućih standarda ili neobavezujućih preporuka. Njih donose međunarodno priznate organizacije od kojih su najpoznatije:

> Međunarodna elektrotehnička komisija (International Electrotechnical Commission - IEC),

$>$ Evropski komitet za elektrotehničku standardizaciju (Committee Europeaen de Norme Electriques CENELEC),

$>$ Institut inženjera elektrotehnike i elektronike (Institute of Electrical and Electronics Engineers IEEE), itd.

\section{OPIS MERNOG MESTA}

Merenja su izvršena na trafostanicama $20(10) / 0,4 \mathrm{kV} \mathrm{u}$ Novom Sadu, Jasku i Kikindi. U pitanju su trafostanice u firmi Energotehnika Južna Bačka iz Novog Sada, fabrika vode Jazak i livnicu Le Belier u Kikindi.

Mrežni analizator je postavljen na nisko-naponskoj strani $(0,4 \mathrm{kV})$. Na slikama 1,2 i 3 može se videti postavka mrežnog analizatora firme „Dranez“ [3], koji je korišćen za merenje i monitoring $\mathrm{u}$ ormanu trafo-ćelije trafostanici preduzeća Južna Bačka, detalj priključenja merni naponskih sondi, kao i jednopolna šema TS Energotehnika - Južna Bačka. 


\section{REZULTATI MERENJA}

Dana 07.08.2019. na nisko-naponskom razvodnom ormanu izvršena su merenja parametara kvaliteta elekričnog napajanja na objektu TS Južna Bačka 10/0,4 kV u periodu od 7 dana. Na slikama 4-16 prikazani su rezultati ovih merenja.

Na slikama 4 i 5 se nalaze dijagrami promene efektivnih vrednosti međufaznih napona $i$ struja $u$ sve tri faze $u$ posmatranom periodu.

Može se videti da je napon varira $u$ standardnim granicama id a neodstupa više od $\pm 5 \%$. Kod struje su uočljivi dnevni porasti potrošnje tokom nedelje, kao i niske vrednosti tokom vikenda, kada su radne aktivnosti u firmi minimalne.

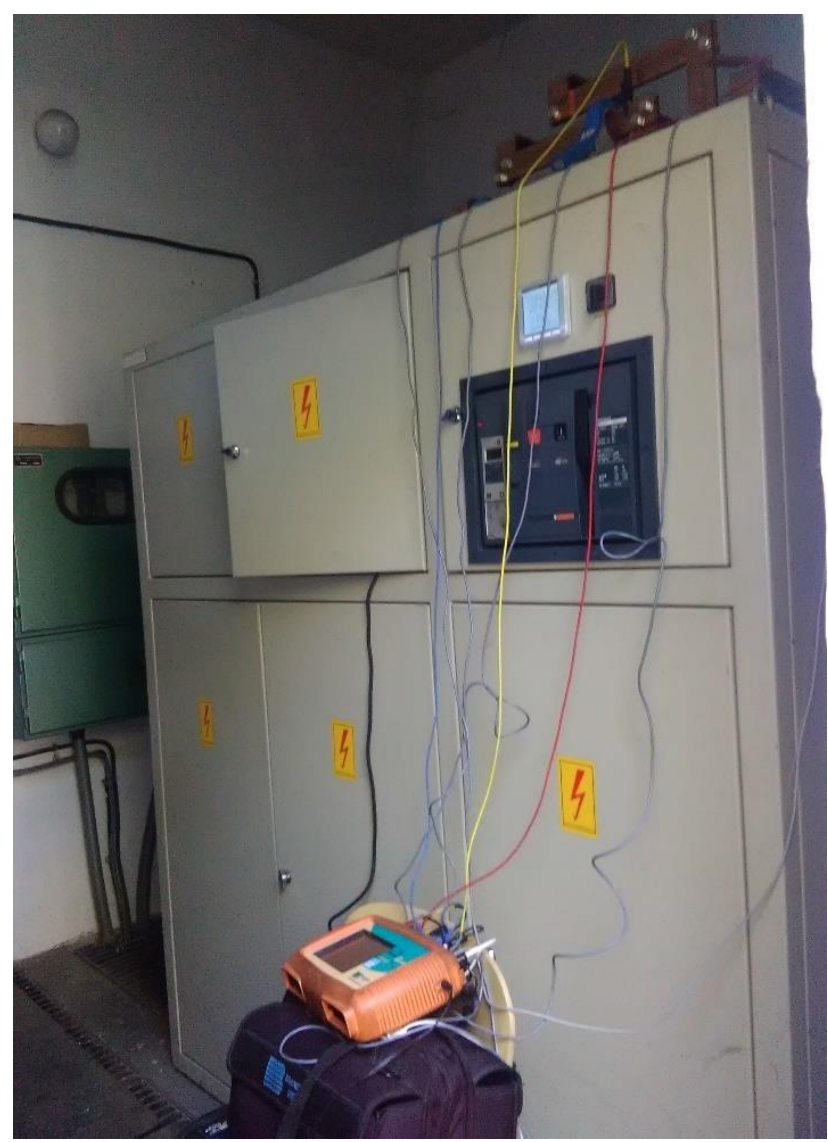

Slika 1 - Orman ćelije nakon postavljanja instrumenta za merenje kvaliteta električne energije

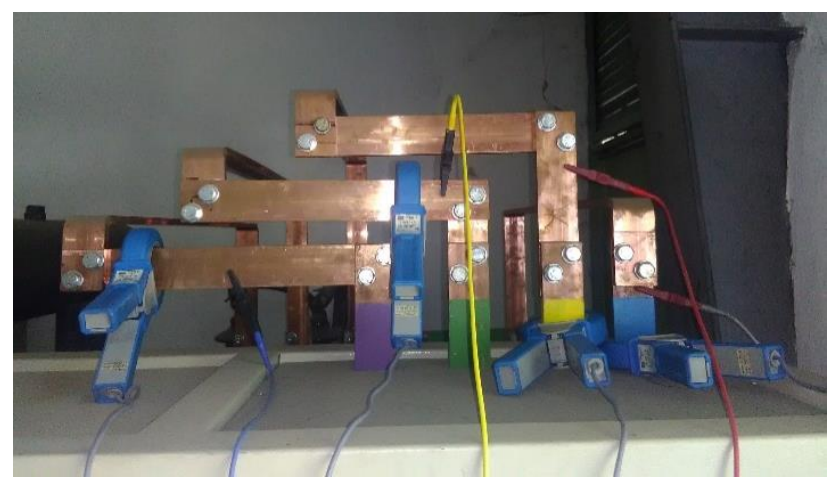

Slika 2 - Strujni i naponski priključci

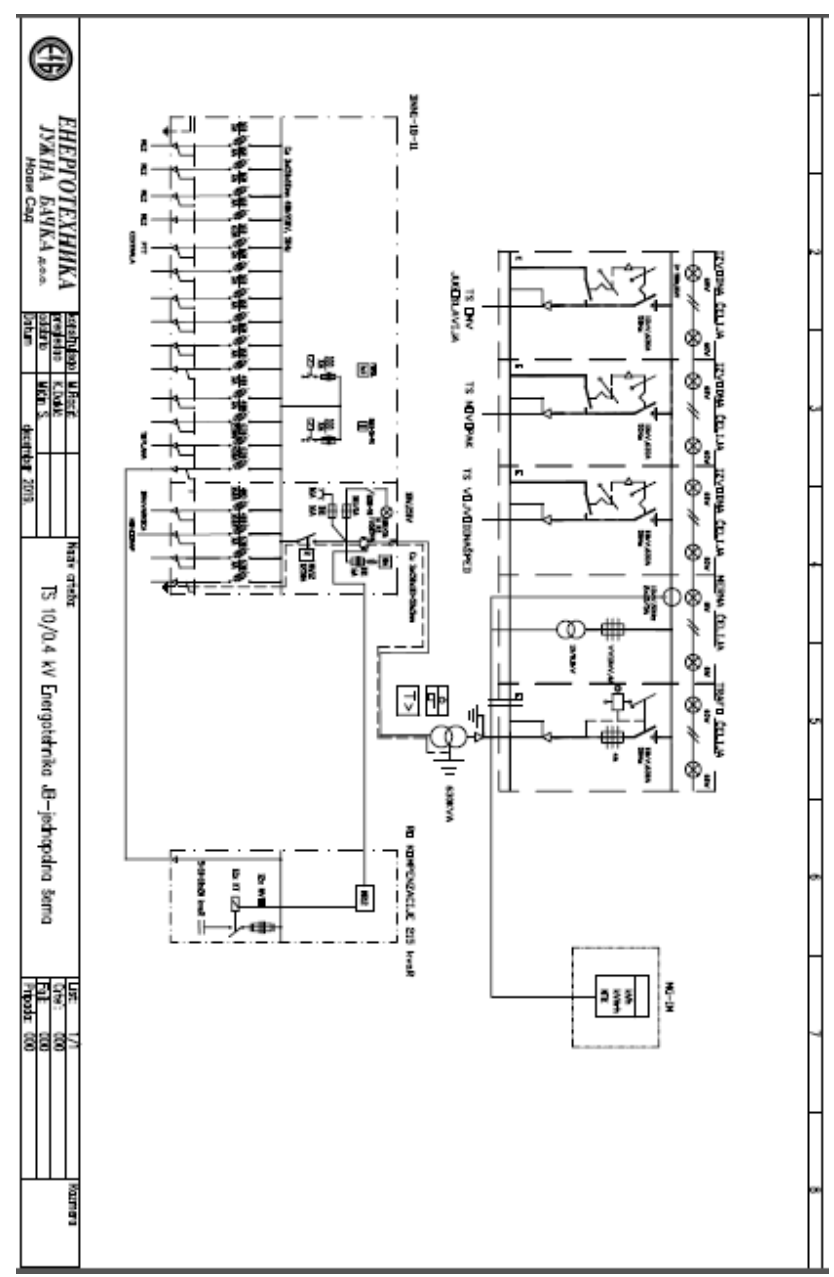

Slika 3 - Jednopolna šema TS Južna Bačka

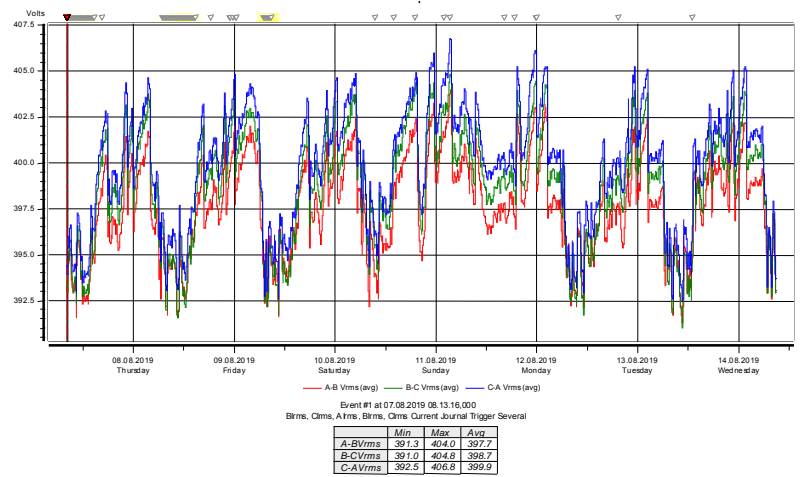

Slika 4 - Promena efektivne vrednosti međufaznih napona u toku 7 dana

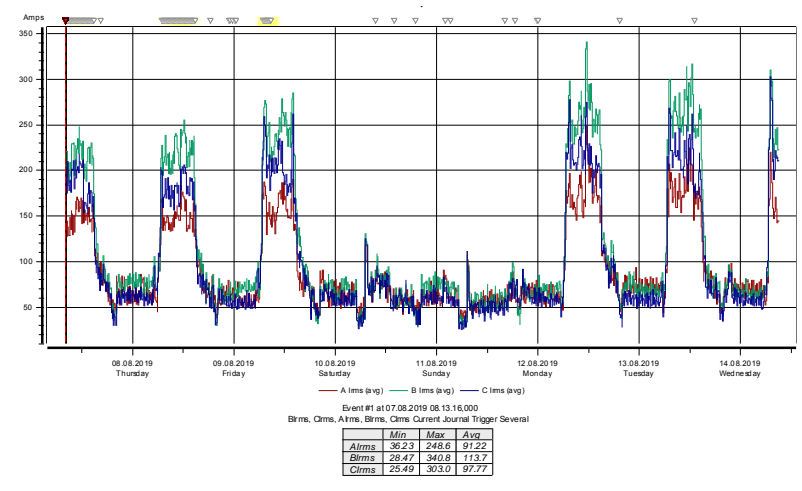

Slika 5 - Promena efektivne vrednosti struja u toku 7 dana 
$\mathrm{Na}$ slici 6 je prikazano kretanje frekvencije u period merenja i može se videti da joj se vrednosti kreću od $49,9 \mathrm{~Hz}$ do $50,09 \mathrm{~Hz}$, pri čemu se ova maksimalna vrednost javlja samo u par mernih tačaka, a pored toga je $95 \%$ vrednosti u granicama $+/-1 \%$, odnosno $100 \%$ u granicama $+4 \%-6 \%$ po standardu EN 50160.

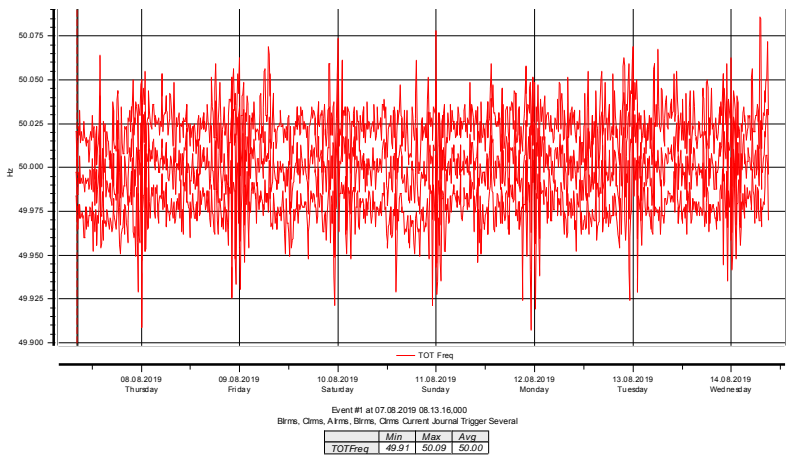

Slika 6-Frekvencija

Na slici 7 je prikazan THD napona koji ne prelazi vrednost od 3,351\% i može se zaključiti da ne postoji povećan THD napona. U granicama je koji je predviđen standardima.

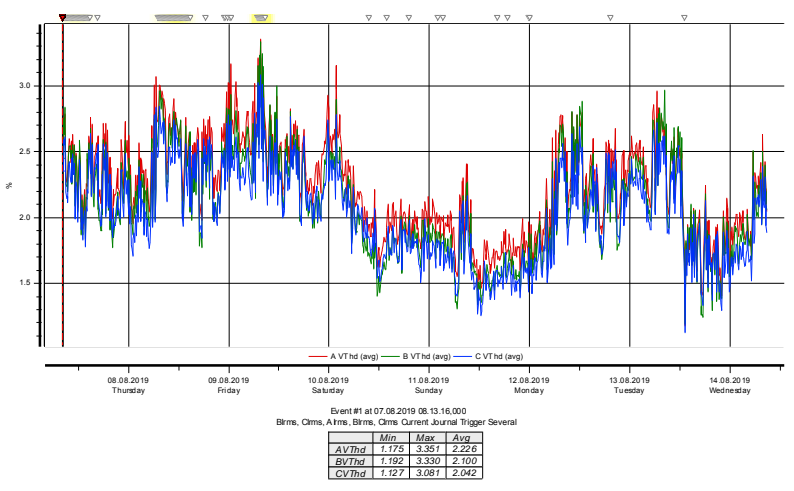

Slika 7 - Promena THDU tokom perioda merenja

U pogledu totalnog harmonijskog izobličenja struja može se zaključiti da postoji povećan THDI. THDI prikazan na slici 8 je blago povišen u odnosu na vrednosti predviđene standardima (preko 20\%)

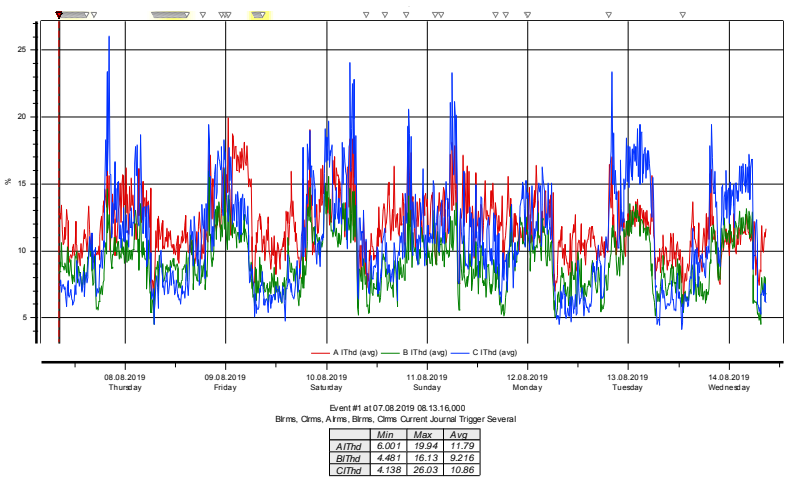

Slika 8 - Promena THDI tokom perioda merenja

Krest faktor napona, prikazan na slici 9, u posmatranom roku od sedam dana ni u jednom trenutku nije prešao očekivanu vrednost od $1,45 \%$, pa u sistemu neće postojati problem pikova napona.

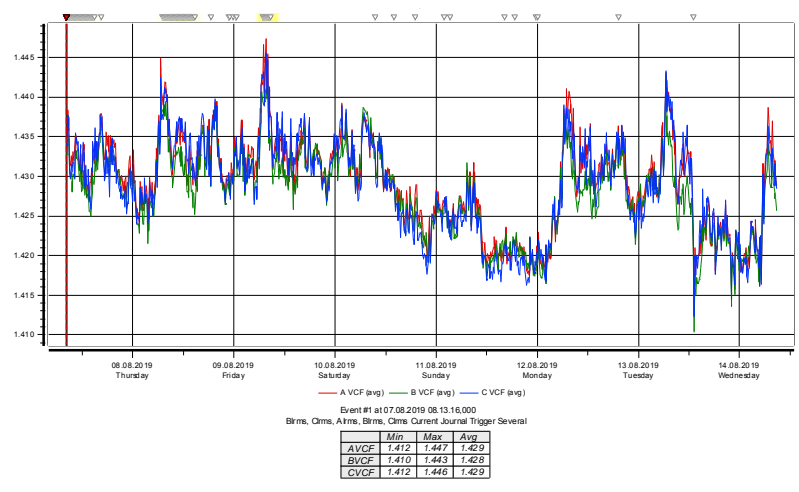

Slika 9 - Promena krest faktora napona u toku 7 dana

Na slici 10 prikazana je promena krest faktora stuje. Sa slike 10 može se zaključiti da i krest faktor struje, kao i u slučaju napona, ne prelazi očekivane vrednosti.

$\mathrm{Na}$ slici 11 prikazane su izmerene promene flikera $\mathrm{u}$ posmatranom periodu. $\mathrm{Na}$ osnovu prikazanih grafika uočljivi su veliki pikovi u sve tri posmatrane faze.

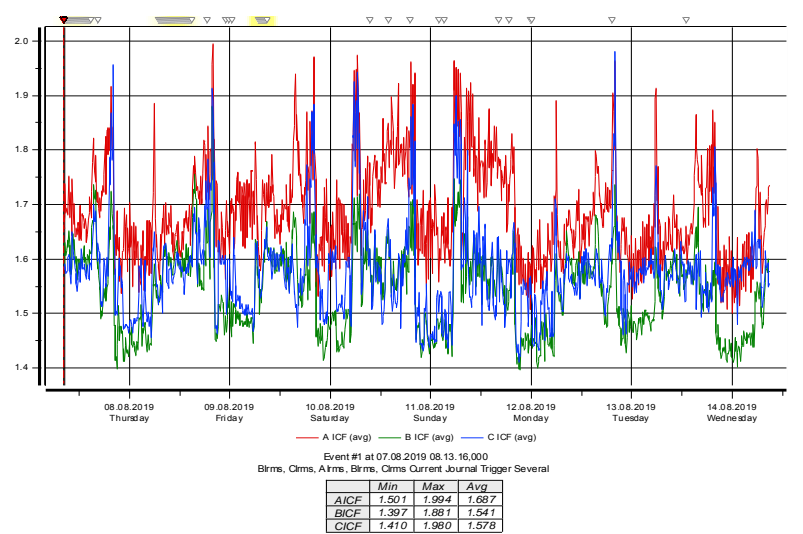

Slika 10 - Promena krest faktora struje u toku 7 dana

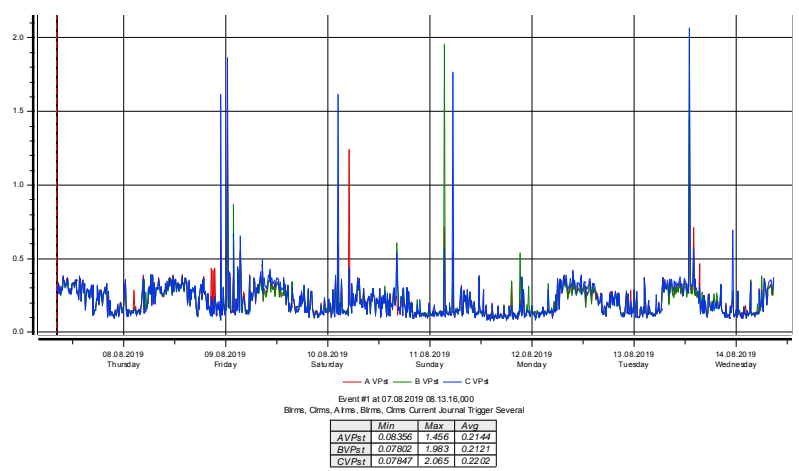

Slika 11 - Promena flikera napona u toku 7 dana

$\mathrm{Na}$ slici 12 prikazana je promena faktora derejtinga transformatora, odnosno $-k$ faktora. Što je veći ovaj factor, to su veći gubici u transformatoru izazvani višim harmonicima, pa se sa slike 12 može zaključiti da $k$ faktor u pojedinim trenucima može predstavljati problem. Olakšavajuća okolnost je ta što kada je $k$ faktor visok, efektivna vrednost struje je mala, pa se transformator neće značajnije pregrejati. Ipak, ovakvi rezultati zahtevaju detaljnije razmatranje $i$ po potrebi preduzimanje odgovarajućih mera za smanjenje nivoa viših harmonika, kao što su pasivni ili aktivni filteri na priključcima nelinearnih potrošača.. 


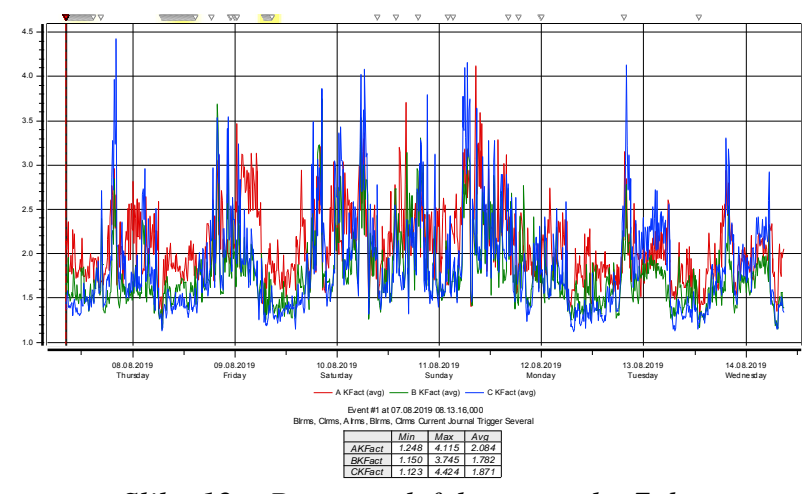

Slika 12 - Promena $k$ faktora u toku 7 dana

Na slikama 13 i 14 prikazani su nedeljni dijagrami aktivne, reaktivne, dok je na slici 15 data promena prividne snage. Na kraju je na slici 16 predstavljena promena faktora snage.

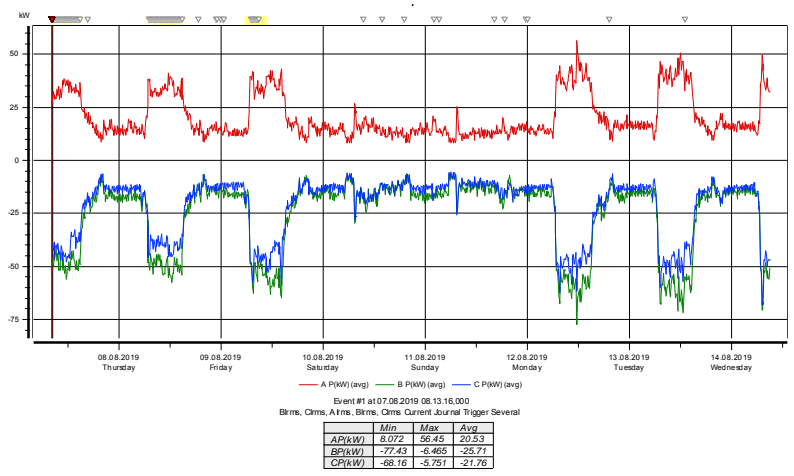

Slika 13 - Dijagram aktivne snage u toku nedelju dana

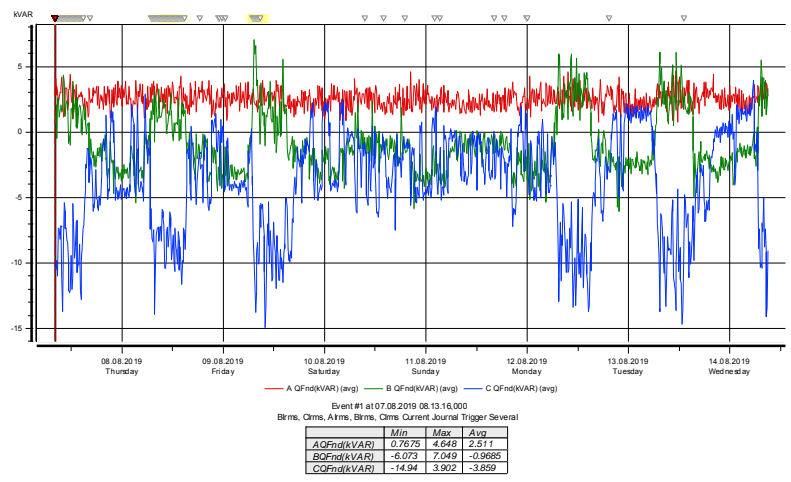

Slika 14 -Dijagram reaktivne snage u toku nedelju dana

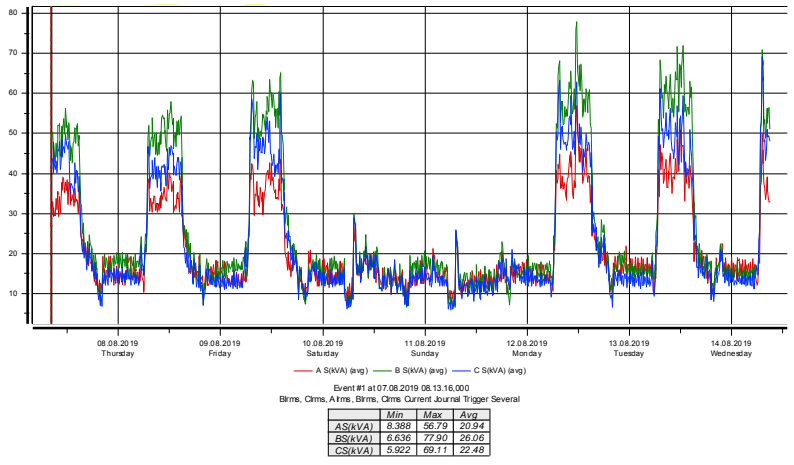

Slika 15 - Dijagram prividne snage u toku nedelju dana

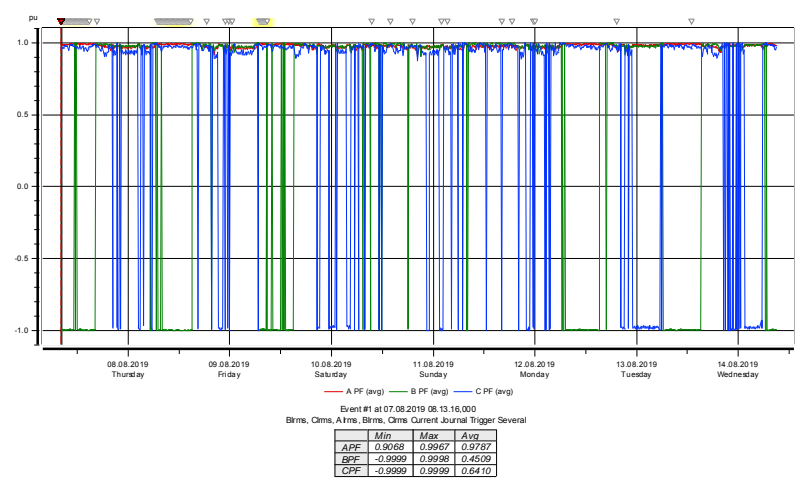

Slika 16 - Promena faktora snage tokom merenja.

Sa prikazanih grafika jasno se vidi da je period povišene potrošnje tokom radnih dana. Za vikend, što je i logično, potrošnja aktivne i reaktivne snage je znatno smanjena posmatrano u odnosu na radne dane.

U pogledu vrednosti faktora snage treba napomenuti da se isti nalazi u opsegu očekivanih vrednosti (od -1 do +1$)$.

\section{ZAKLJUČAK}

Sa aspekta kvaliteta napona nema većih problema i svi indikatori kvaliteta električne energije spadaju u okvire diktirane stanardima. U većini slučajeva THDU je oko $1 \%$, neretko i manji od $1 \%$. Sa aspekta kvaliteta struje postoji veće odstupanje i svi indikatori ukazuju na to da kvalitet struje nije zadovoljavajući. Razlog su dominantni nelinearni potrošači na što ukazuje veliko harmonijsko izobličenje struje, koje je iznad okvira predviđenih standardima. Da bi se to nedvosmisleno utvrdilo trebalo bi izvršiti detaljnu analizu potrošača i utvrditi pojedinačni negativni uticaj potrošača na kvalitet električne energije.

\section{LITERATURA}

[1] V. A. Katić, A.Tokić, T.Konjić, "Kvalitet električne energije”, TEMPUS-CEFES, Fakultet tehničkih nauka, Novi Sad, 2007

[2] M. M. Kostić, "Kompenzacija reaktivne energije $i$ viši harmonici u električnim mrežama”, Elektrotehnički instiut Nikola Tesla, Beograd, 2014

[3] Power guide 4400, User's guide, Dranetz, New Jersey, 2005

\section{Kratka biografija:}

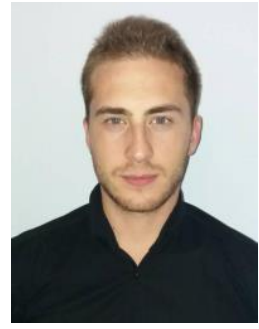

Mile Racić rođen je u Zrenjaninu 1992. godine. Osnovne studije završio je na Fakultetu tehničkih nauka 2017. iz oblasti Elektrotehnike i računarstva Energetska elektronika i električne mašine. Master rad je odbranio 2021. godine, na istom fakultetu, na smeru Energetika, elektronika i telekomunikacije - Energetska elektronika i električne mašine. 